\title{
The use of knowledge assets: modelling the potential effect of adding innovators to low-innovation and high-innovation SMEs
}

\author{
Robert B. Mellor \\ School of Computing and Information Systems, \\ Kingston University, \\ Penrhyn Road, KT1 2EE, UK \\ Email: r.mellor@kingston.ac.uk
}

\begin{abstract}
SMEs rarely possess formal intellectual property (IP) in the sense of patents, etc. Broadly speaking, SMEs reap relatively short-term Schumpeterian profits by means of incremental innovation, where managing internal knowledge networks for 'mutual inspiration' can give rise to significant competitive advantages. Unfortunately estimates as to the best timing, how much benefit could be reaped and considerations of the organisations knowledge framework for future development are, at best, vague. To address this issue, a $3 \mathrm{D}$ quantitative fold is presented that pertains to a novel knowledge-based theory of the growth of SMEs via their knowledge assets and that contributes to a model that case studies can test. The fold allows quantitative estimations of the potential value of knowledge using Monte Carlo modelling (i.e., shooting virtual balls down the fold and analysing their final scatter distribution). Results indicate that adding middle-management innovators to low-innovation SMEs can contribute markedly to potential financial performance but adding innovators to high-innovation SMEs does not provoke an absolute increase in returns, but performance levels are reached earlier. In all cases potential financial performance was dramatically improved by laying down an innovative stratum early in SME development rather than on top of an already-established less-innovative middle management layer.
\end{abstract}

Keywords: growth and financial returns; innovation; management; modelling; organisation; SME.

Reference to this paper should be made as follows: Mellor, R.B. (2014) 'The use of knowledge assets: modelling the potential effect of adding innovators to low-innovation and high-innovation SMEs', Int. J. Knowledge-Based Development, Vol. 5, No. 4, pp.367-380.

Biographical notes: Robert B. Mellor is a fellow of the Royal Institution and holds doctorates in various academic disciplines including innovation, computing and biology and is author of over 120 scientific publications in reputable journals, including, e.g., Nature. In addition to his scientific publications, he has written ten books, including four on innovation and entrepreneurship and three of his books have appeared in foreign translations. $\mathrm{He}$ has won a number of international prizes for his works, is an active consultant with twelve years industrial experience and is expert advisor to several national governments and the European Union. He currently works in computing, information systems and mathematics at Kingston University, London. 


\section{Introduction}

The acknowledged importance of SMEs to the national economy (e.g., Birch, 1987) has led many researchers to explore if any generic theory can explain or encourage their growth, spread and success (recently reviewed and contributed to by, e.g., Leitch et al., 2011; Storey 2011). Certainly the use of knowledge has tentatively been identified as a factor contributing to business success by a large variety of authors from Boisot (1995) to, e.g., Clarysse et al. (2011). However estimates as to the best timing, how much benefit could be reaped and considerations of the organisations knowledge framework for future development are, at best, vague. Indeed no precise link has convincingly been elucidated by empirical research, but it is tempting to speculate that knowledge recombination to new innovative forms could contribute to lowering asset erosion in small organisations (SMEs) and may well contribute positively to asset mass efficiencies in those organisations large enough to have acquired sufficient mass. Nevertheless although Kotler and de Bes (2003) state; "Companies need to innovate if they are to grow and prosper" little has changed between the early work of Holmes and Zimmer (1994) who state "an operational framework that distinguishes growth from non-growth small businesses does not exist" to Atherton and Hannon (2001) who again remarked that there has been "a paucity of research on how innovation can arise and spread in small companies". Contemporary research (e.g., Suppiah and Sandhu, 2011) still do not fill this gap in our understanding. Let us think back to over 30 years ago when Porter (1980, p 74) stated that "companies achieve competitive advantage through acts of innovation" and again ten years after that when (Porter 1990) said that "much innovation is mundane and incremental, depending more on an accumulation of small insights than on a single major technological breakthrough". The finding that the sum of many incremental innovations can have a very large impact on markets, value and technology is also supported by a plethora of other authors (e.g., Bessant, 1999; Birkinshaw and Sheehan, 2002). This implies that, especially when applied across the board to SMEs, formal invention actually plays a minor part in the process of value creation across mercantile society - although specialised high-tech start-ups may form an obvious exception to this broad generalisation. Nonetheless and as pointed out above, there still appears to be a link between utilising knowledge for incremental innovation and this leading to growth and concrete financial returns, for example Farrell (2000) polled 2,000 organisations in Australia and found:

1 that market orientation is positively related to a learning orientation within the company, but that

2 a learning orientation has a stronger significant positive effect on business performance than does market orientation.

Carneiro (2000) also agreed that "... knowledge development is a fruitful background where incremental innovation may be attempted ..." Thus despite being hard to pin down the fact remains that if incremental innovations are important - perhaps even the most important type of innovation when considered in an SME context - then it could be interesting for SME management and investors to understand how and where incremental 
innovations arise. In a seminal work, Iansiti (1993) indicated that incremental innovations arise preferentially in certain individuals and refers to individuals able to sustain meaningful and synergistic relationships with others as possessing 'T-Shaped Skills', referring to depth in a particular discipline but combined with a breadth of understanding of other disciplines. This view has been expanded upon to include 'a-shaped skills', multi specialists possessing dual deep (often technical) skills and an accessible overview of this subject can be found in, e.g., Yang et al. (2008). The role of multi specialists in particular, has recently re-surfaced and has been the subject of much debate starting with Katz (2004) who said; "research studies ... indicate that the broader the range of skills and abilities ... the more likely it is that that person will ... become a more effective and successful contributing member of the organisation ..." and there is increasing evidence connecting multi-skilling (also variously described as T-shaped or A-shaped skills) with increased innovations as contrasted with the number and level of innovations created by people with a single specialisation (Tsai and Huang, 2008). Mellor, (2005, 2011) speculated that the amount of communication between two individuals needed to create 'mutual inspiration' or another innovative outcome is subject to transaction costs (Williamson and Masten, 1999) but that in the multi-skilled, such transaction costs are negligible (Mellor, 2005). Due however to environmental and market uncertainty, statistically-valid results from rigorous long-term experiments can rarely be obtained.

The idea of creating a 3D model landscape is gaining acceptance; Kauffman (1993) used ideas of a 'fitness landscape' in evolutionary biology, moving agents across a 'fitness valleys' to higher 'fitness peaks'. At higher points in the landscape, survival is more likely and the risk of extinction reduced. This type of modelling has more recently become popular with business analysts applying it to anything from situated learning theory (Yuan and McKelvey, 2004) to manufacturing strategies (McCarthy, 2008). While these results certainly do not represent reality in anything more than an analogy, they do contribute to a model that case studies can test. Therefore a relatively simple mathematical modelling approach has been adopted in order to clarify some basic principles. Preliminary results of modelling the effects of departmentalisation, social exclusion zones, task forces, multi-skilling and formal intellectual property (IP) on innovation potential have previously been presented by Mellor (2011) and on SME development by Mellor (2014).

\section{Modelling}

\subsection{Modelling methods 1 , constructing the $3 D$ fold}

Measuring the potential for increased innovation was accomplished exactly as described previously (Mellor, 2011, 2014). Briefly, A peer-to-peer model was constructed where people in an organisation are represented as nodes (the number of people is represented by $\mathrm{P}$ ), and are joined by ties. The number of links or ties between nodes is the diversity innovation (DI) number. As the DI number increases the potential for knowledge recombination into innovation increases. When two individuals enter into a 
communicative relationship, then a communication pathway (called a link or 'tie') opens, i.e., the DI number reaches 1 . As long as the number of people involved is larger than 3, then the number of pathways is related to the number of people involved and this relationship can be expressed by a simple equation (note that an asterisk, *, is the mathematical symbol for multiply):

$$
\mathrm{DI}=\frac{\mathrm{P} *[\mathrm{P}-1]}{2}
$$

Using this equation the amount of potential DI in an organisation as it grows and acquires more employees can be seen in Figure 1.

Figure 1 Growth of DI with number of employees from 0 to 250 (see online version for colours)

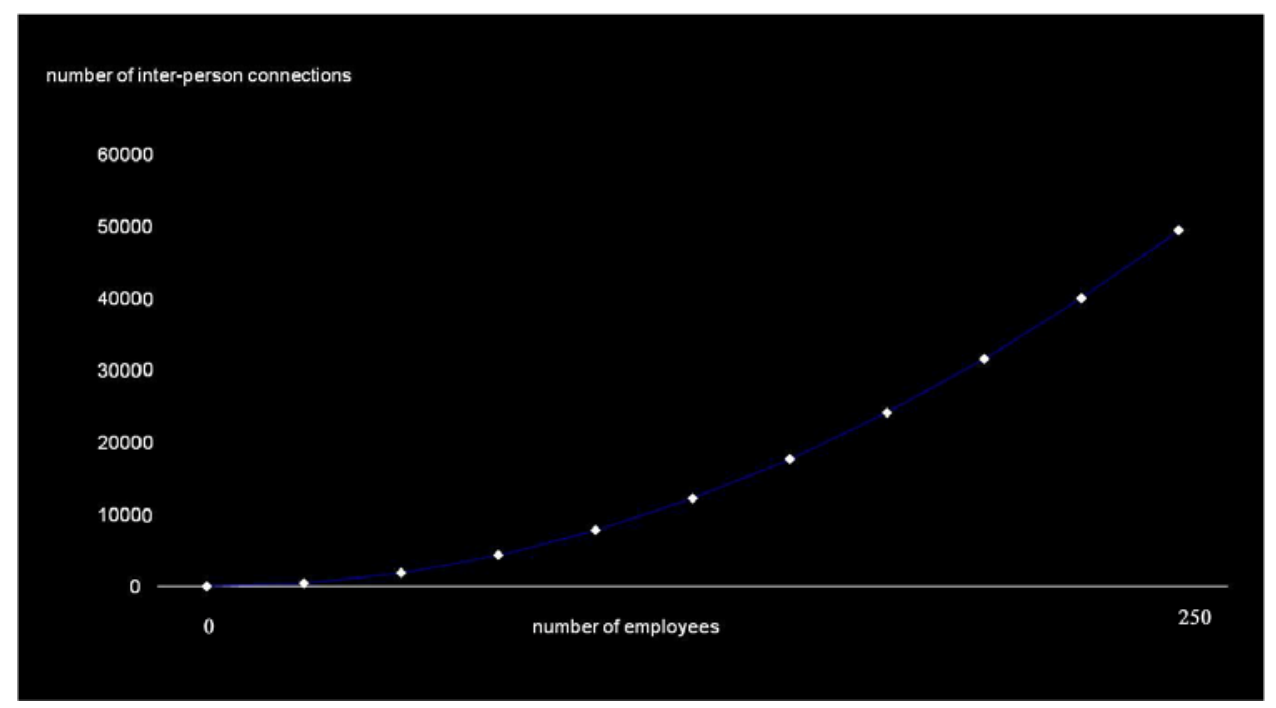

However widespread rampant knowledge sharing in theory is, and however high the potential for consequent recombination of diverse knowledge into useful innovation is, it is unfortunately prevented in practice by the concomitant increase in transaction costs for communication: From the DI Equation we can see that in a company with a little over 100 employees, it would take approximately 600 hours or 16 man-weeks of working time just for the employees to talk to each other for five minutes, excluding that any employees got a chance to repeat any conversations or do any work. Each further employee hired would take approximately ten man-hours to talk to existing employees for five minutes each. Clearly these are considerable transaction costs both in terms of salary as well as in loss of productivity.

Furthermore as an organisation grows, unfettered knowledge sharing is no longer possible because at around 50 employees, transaction costs force SMEs into a policy of departmentalisation, and the effect of forming departments is to decimate the DI number (Figure 2). 
Figure 2 DI number in a population between 1 and 250 nodes (employees), splitting the organisation into equally-sized parts when each department reaches size 60 (see online version for colours)

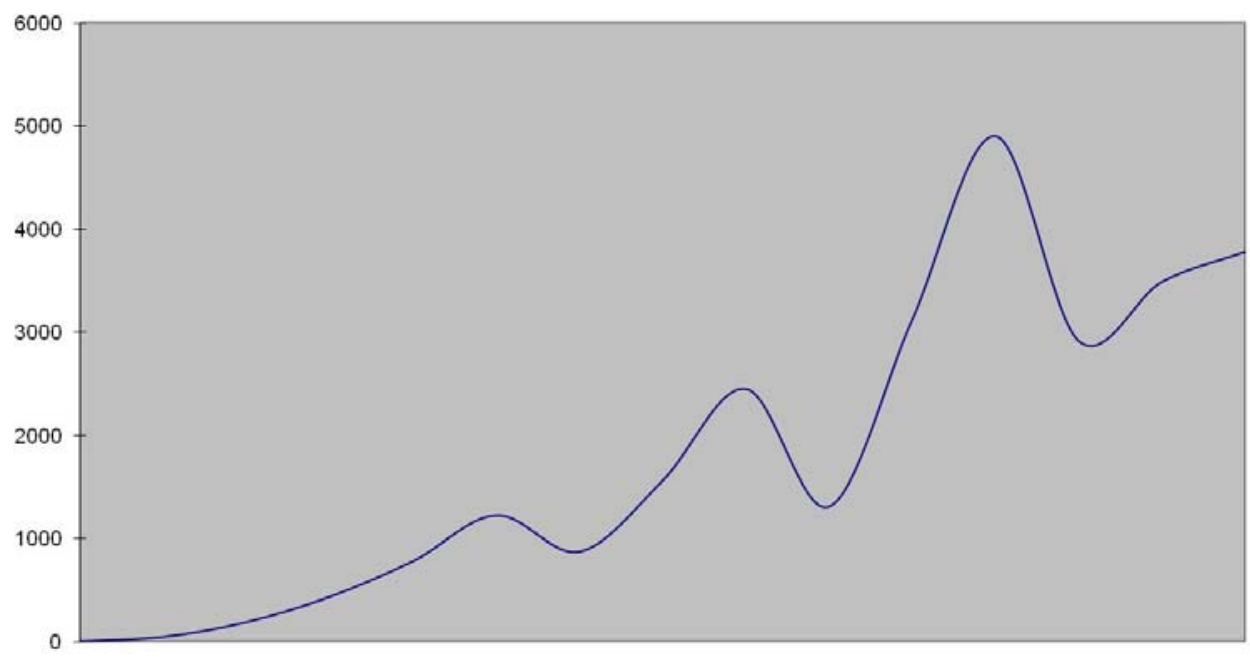

Notes: Please note that this model assumes that knowledge transmission through information gatekeepers (nominally heads of the departments) functions perfectly. The curve has been subjected to a smoothing algorithm because even as departments divide, intra-employee links or ties will remain for some time.

Having established some key values on the $\mathrm{X}$ and $\mathrm{Y}$-axes, the units on the Z-axis can be established. At first this looks unlikely, because there are simply no units for innovation ('kiloinnos', etc.), however a $1-100 \%$ scale can be used where the value is the amount derived from the maximum (100\%) possible using for an organisation of known size from the DI equation, i.e., benchmarked using the absolute value obtained from employee number.

The third dimension of the model is given by a J-curve, because the J-curve represents a transition where - put simply - things get worse before they get better. In this fold the numbers on the Z-axis are derived from business process reengineering (BPR) literature. At the lowest point the value of a commercial company undergoing BPR may be decreased by $40 \%$. This means that an organisation worth ten million will be down to six million. This is the practical value seen and reported by BPR professionals, e.g., McKinsey, Accenture, Deloitte and others, but obviously it does not represent the lowest possible value, because there is nothing to stop the company worth ten million from going down to zero, or even minus ten million, it is just that if the value drops below the $40 \%$ rule of thumb, then the organisation will probably not survive the BPR operation.

Similarly we can estimate the difference in height of the starting and finishing points; always subject to the difficulties in measuring value as mentioned above. Taking a traditional company as starting point and transforming it, a successful BPR project will, 
at maturity, approximately triple the value of an organisation (noting that exact figures are not possible to, e.g., the nature of accounting practices, inflation and that the world will have moved on). Higher values - reaching up to 10 - have been reported by, e.g., Lillrank and Holopainen (1998), but these are regarded in the industry as being very special cases and are much trickier to compare as they often pertain to newer companies, i.e., comparing internet-based companies like Amazon with a rather theoretical non-internet baseline. The values used in this publication and before (Mellor, 2011) in constructing the J-curve are given in Table 1 .

Table 1 An overview of the data used in preparing Figure 3

\begin{tabular}{lcccc}
\hline $\begin{array}{l}\text { Percent use of } \\
\text { innovation }\end{array}$ & $\begin{array}{c}\text { Average } \\
\text { wage }\end{array}$ & $\begin{array}{c}\text { Profit per } \\
\text { employee }\end{array}$ & $\begin{array}{c}\text { Income per } \\
\text { worker }\end{array}$ & $\begin{array}{c}\text { Minimum annual } \\
\text { turnover }\end{array}$ \\
\hline 0 & 20,000 & 13,014 & 33,014 & $8,253,500$ \\
10 & 20,000 & 11,447 & 31,447 & $7,861,750$ \\
20 & 20,000 & 9,640 & 29,640 & $7,410,000$ \\
30 & 18,000 & 8,194 & 26,194 & $6,548,500$ \\
40 & 19,000 & 7,240 & 26,240 & $6,560,000$ \\
50 & 20,000 & 9,399 & 29,399 & $7,349,750$ \\
60 & 21,000 & 14,460 & 35,460 & $8,865,000$ \\
70 & 25,000 & 20,485 & 45,485 & $11,371,250$ \\
80 & 30,000 & 26,510 & 56,510 & $14,127,500$ \\
90 & 35,000 & 33,740 & 68,740 & $17,185,000$ \\
100 & 40,000 & 40,006 & 80,006 & $20,001,500$ \\
\hline
\end{tabular}

Note: Values in British pounds as of 2008.

Using these values (Mellor, 2011), J-curve can be constructed (see Figure 3).

Figure 3 The J-curve as derived from Table 1

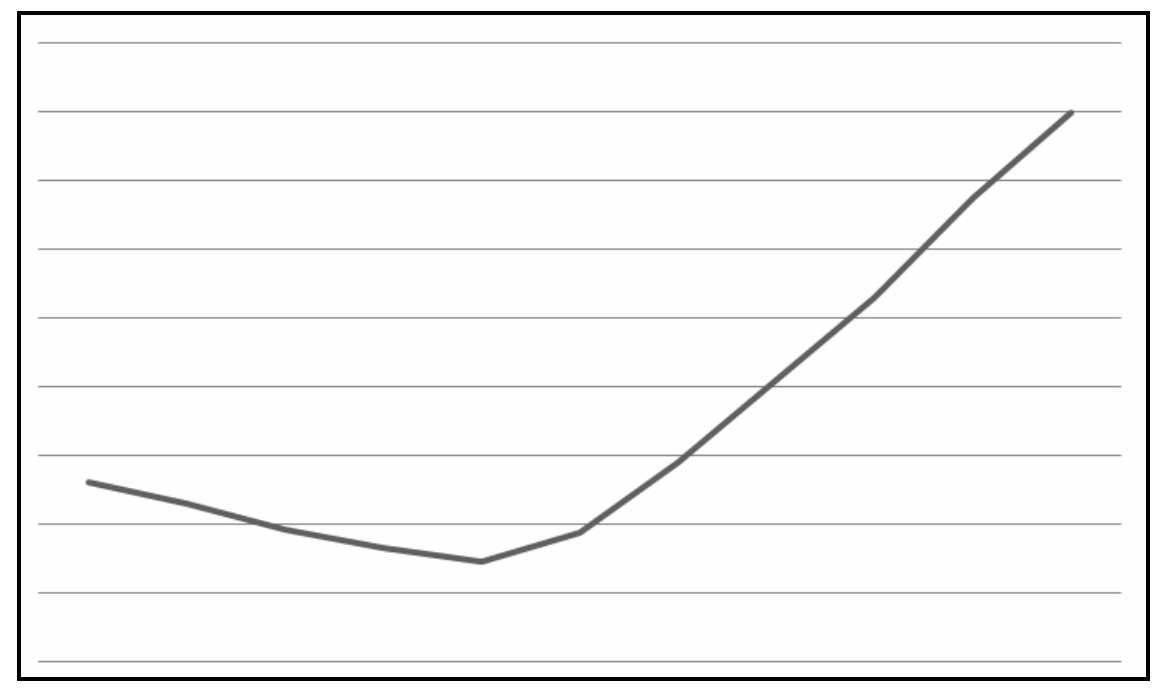


From Table 1 the percent use of innovation can be plotted against financials, resulting in the J-curve shown in Figure 3. This curve also represents the expected curve of a BPR operation taking a low-innovation organisation ('Dickensian') from the left to a higher state ('Schumpeterian') on the right, the high-value organisations on the right representing those able to use Schumpeterian innovation to create more value. These are the 'gazelles' of the sector. Combining Figure 2 with Figure 3 results in the 3D fold shown in Figure 4.

Figure 4 The knowledge valley fold (see online version for colours)

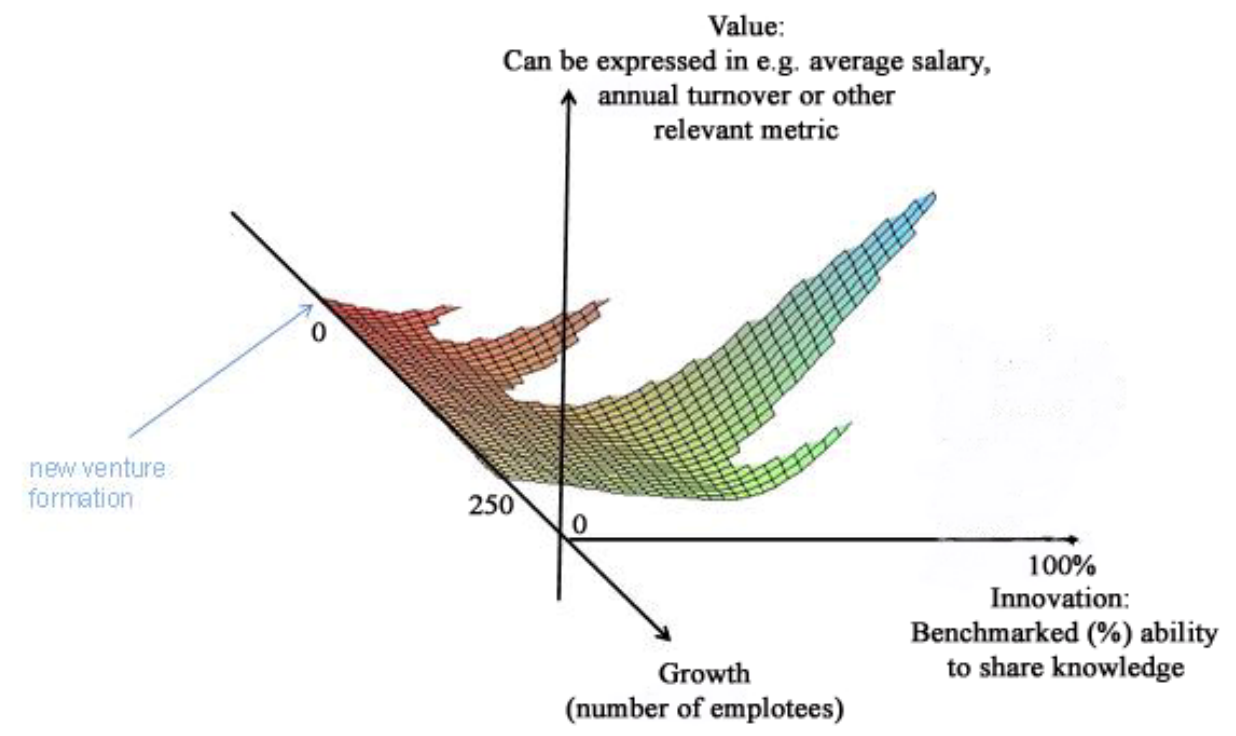

Note: In this publication the previous nomenclature is adopted for the sake of clarity and continuity, those organisations with a low degree of openness to innovation are called 'Dickensian' and those with a high degree are called 'Schumpeterian'.

Source: Adapted from Mellor (2011)

\subsection{Modelling methods 2, Monte Carlo modelling}

The modelling consists of injecting virtual 'Monte Carlo' balls randomly down the valley from the origin along connections between nodes whilst distorting the net (the fabric of the valley) according to selected variables ('factors') which can be programmed into the algorithm being investigated, and then plot the result so that trends can be discerned. Since all nodes are directly connected to each other, they are always 'nearest neighbour' and sweeper code was thus added prevented to prevent balls going backwards, exactly as described previously (Mellor, 2011).

The experimental run ends when the last of 1000 balls reach the right-hand side of the valley - their exit points being impressed as a scatter plot on the J-curve (the Z-axis). Monte Carlo balls bowled down the valley from the origin, and where the valley consists 
of a completely uniform net, will arrive in a random fashion, i.e., they will arrive on the Z-axis showing no peaks or troughs. Plots are derived by graphing the number per unit length against unit on the Z-axis. The Z-axis represents value, so a peak of Monte Carlo balls arriving there strongly implies an increase in value for the organisation. It is possible to distort the net - add factors - and then see by analysing the resulting scatter plot if the factor under investigation has added any value or not. Each experimental run was repeated ten times.

Figure 5 Illustrating that Monte Carlo balls bowled down the valley (see Figure 4) from the origin will arrive in a random fashion (Figure $5 \mathrm{~A}$ ) but variations in the net will result in various scatter plot outcomes (Figure 5B) (see online version for colours)

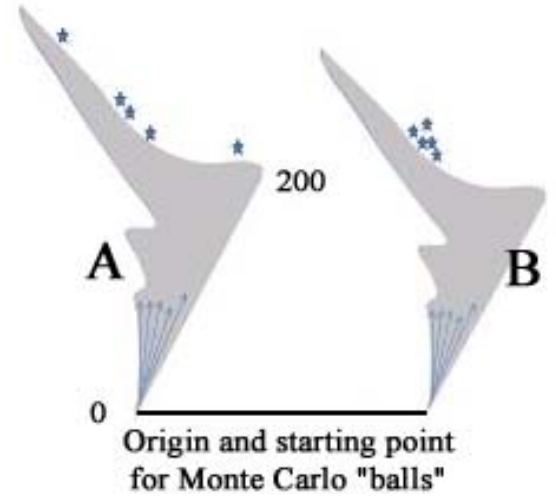

If a statistically significant correlation exists between the factor being tested and adding value, then the scatter plot on the Z-axis will form a probability density function (a Gauss curve, also known as a Bell curve or normal curve). On a classical Gaussian distribution, the scale parameter (small sigma, $\sigma$ ) is 1.00 . How much a given curve varies from a classical Gaussian distribution can be assessed by measuring the scale parameter of the curve; the more it diverges from 1.00 the less correlation there is. Values of scale parameter below 1.00 indicate a very sharp peak and those over 1 indicate a spread peak, i.e., of low correlation. Values of 3.0 and over indicate a correlation that, for practical purposes, is so weak that it can be ignored.

Those with a multi-specialised background [possessing 'T-shaped' or 'A-shaped' skills (Tsai and Huang, 2008; Mellor, 2005)] are likely to be highly qualified and thus may be assumed to work in middle management. Accordingly the second dimension (value) in knowledge valley can be converted from company annual turnover to salary, and a 'knowledge trail' (Mellor, 2011) spanning a reasonably wide band of middle management salary inserted (Figure 6A). This band thus occurs on both the left and right-hand sides of the curve on the Z-axis, forming a bifurcating pathway as shown in Figure 6B.

Innovators are represented not as one node, but as two overlapping nodes, i.e., that no tie is needed to traverse between the nodes. This is done to represent the lack of transaction costs for communication in this individual, so in this case the Monte Carlo ball can progress two nodes down the fold without incurring 'costs'. 
Figure 6 Figure 6A illustrates that if one takes the J-curve (Figure 3) as staff salary and inserts a band approximating a mid-managerial salary (the possible positions of multi-skilled individuals represented by circles), that the areas on the Dickensian and Schumpetrian slopes will be distinct (see online version for colours)

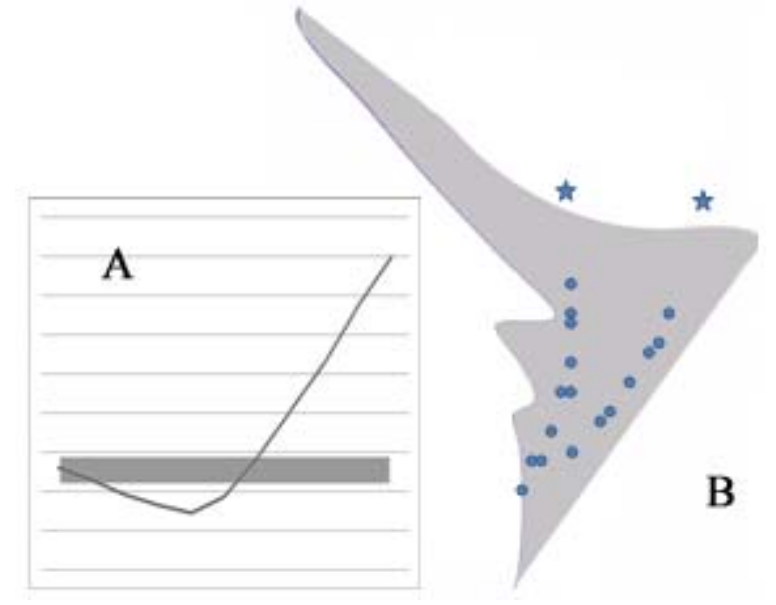

Note: Figure 6B illustrates how this looks in 3D: the bifurcating knowledge trail obtained when choosing similar salary heights at both sides of the knowledge valley fold results in a Y-shaped pathway which may retain Monte Carlo balls and deposit these in separate scatter plot probability densities (indicated by stars).

\section{Analysis and findings}

Where the valley consists of a homogenous and uniform net, the Monte Carlo balls from the origin will arrive in a random fashion. Placing 100\% innovators longitudinally along the pathways described resulted in scatter distribution apparently exhibiting the characteristics of a probability density function; however the curves obtained from repeating the process several times showed this curve not to be Gaussian but rather to be platykurtic, i.e., where the peak of the distribution is flattened. Table 2 shows that even with $100 \%$ innovators on a knowledge trail, the scale parameter $(\sigma)$ did not achieve unity (1.0), which it would have to do, in order to be a Gaussian distribution. Values of scale parameter, small sigma $(\sigma)$ of three and above were discards because values above 3 are insignificantly different from an even line.

Thus the number of innovators down the knowledge trail, was adjusted until scatter plots with a scale parameter (small sigma: $\sigma$ ) of minimum 1.5 was reproducibly achieved and where the location parameter $\mu=1$ (i.e., the location parameter was centred on the intersection of the knowledge trail with the flattened J-curve). This more realistic cumulative distribution function was first obtained when the ratio of overlapping nodes to non-overlapping nodes was $1: 1$, i.e., every second person in the knowledge trail was a multi-skilled potential innovator. This was the case (i.e., the difference in $\sigma$ was not statistically significant) if the overlapping nodes were distributed randomly along the knowledge trail or if deliberately placed in every second position. 
Table 2 The effect of the number of innovators along the bifurcating pathway on the value of the scatter plot scale parameter (small sigma, $\sigma$ )

\begin{tabular}{lc}
\hline Percent innovators & Value of scale parameter $(\sigma)$ to with a confidence of $>90 \%$ where $n=10$ \\
\hline 100 & 1.12 \\
90 & 1.16 \\
80 & 1.20 \\
70 & 1.26 \\
60 & 1.38 \\
50 & 1.50 \\
40 & 1.78 \\
30 & 2.18 \\
20 & 2.99 \\
\hline
\end{tabular}

Figure 7 The impact of spontaneous knowledge trails formed by overlapping nodes in areas to the left and right of the J-curve (i.e., possible effect on innovation and thus, by implication, value, of a multi-skilled middle management layer) (see online version for colours)

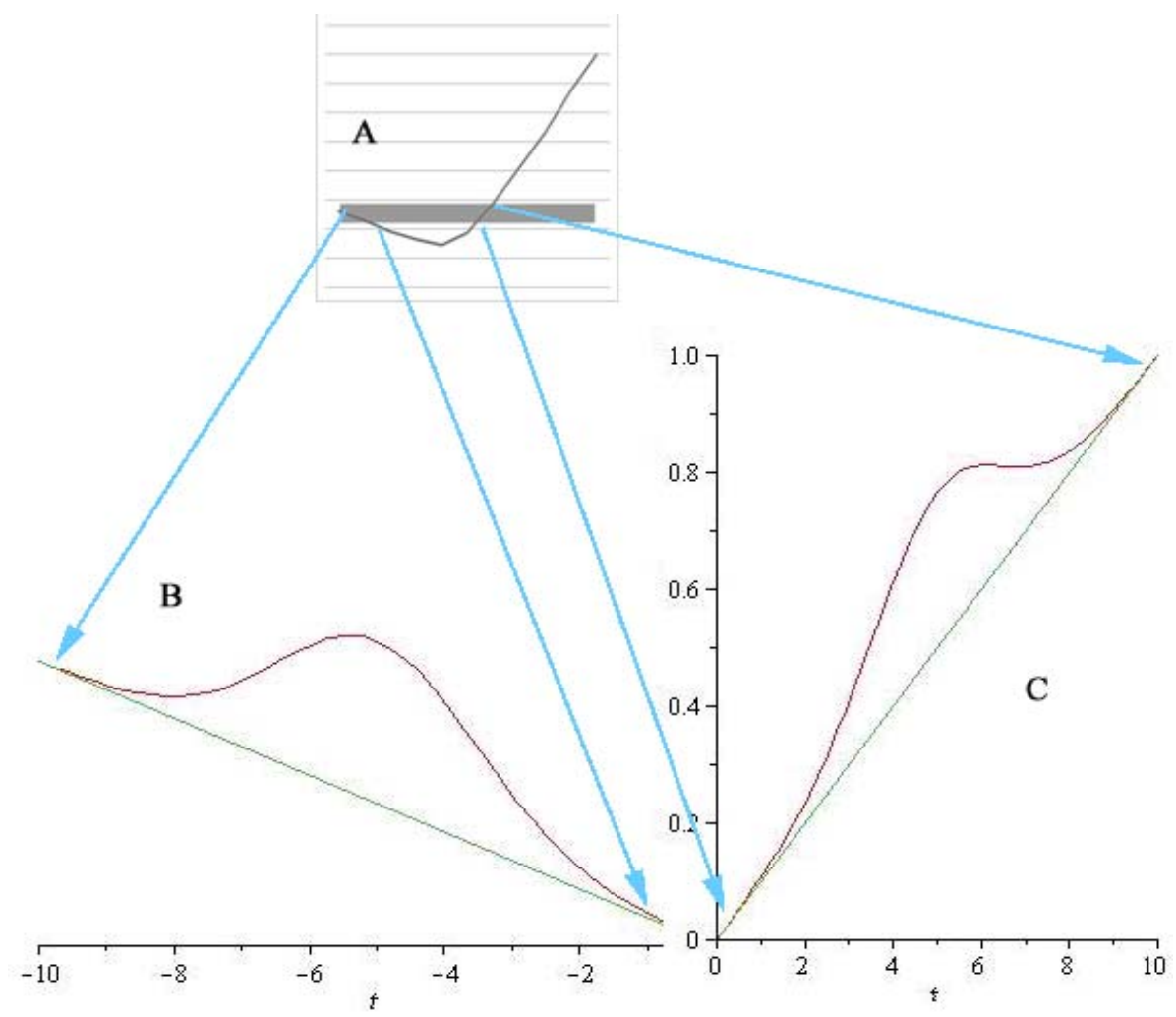

Notes: Showing (Figure 7A) the relationship between placing on the J-curve (see Figure 6A) and Figures 7B and 7C. Figure 7B scatter plot values on the 'Dickensian' slope and Figure 7C on the Schumpetrian slope. 
As Figure 7 shows, companies showing a low percent of use of innovation (i.e., being on the left, Dickensian, side of the J-curve) appear to be able to profitably use multi-specialised individuals in middle management and indeed things may seem to get quite a lot better (remember the vertical axis is value) as the organisation opens up to innovation and change. However, as they proceed along the skewed Gauss curve (moving right) they approach a decline, the nature of which could be very diverse depending on branch and industry, but in any case may be disadvantageous.

Figure 7 also shows that companies showing a high percent of use of innovation (i.e., being on the right, the Schumpeterian, side of the J-curve) can likewise profitably use multi-specialised individuals in middle management. The model indicates that only low or no risk is associated with this strategy and, if it works, things may get much better very rapidly indeed. After this gain in value is realised, added value will reach a drained plateau and level off. But the scatter plots show that when the plateau is reached, developing more multi-skilled knowledge trails, or increasing the numbers/density of multi-skilled individuals (i.e., hiring more) on existing knowledge trails, should not have much further effect. If the effect of these innovators is not fully aligned with the core competencies of the mother organisation, then value can still be extracted by intrapreneurial (spin-out) activities, should the original organisation be sufficiently entrepreneurial.

In order to investigate the effect of longitudinal distribution of innovators further, a more massive inequality in innovator distribution along the bifurcating pathway was investigated: Innovators were distributed along the bifurcating pathway using a Pareto distribution, firstly partitioning $80 \%$ of innovators upstream in the first half of the knowledge valley fold, i.e., earlier in the history of the organisation, in the area 0-100 employees, and secondly partitioning $80 \%$ of innovators downstream in the second half of the knowledge valley fold, i.e., in the area 100-200 employees. A random longitudinal distribution (as before) was used as an internal reference. Table 3 shows that the effect of massive inequalities in distribution was very clear.

Table 3 The effect of the Pareto distribution of innovators along the bifurcating pathway, on the value of the scatter plot scale parameter $(\sigma)$

\begin{tabular}{lccc}
\hline & $\begin{array}{c}\text { 80 upstream: } \\
\text { 20 downstream }\end{array}$ & $\begin{array}{c}\text { Random } \\
\text { (control) }\end{array}$ & $\begin{array}{c}\text { 20 upstream: } \\
\text { 80 downstream }\end{array}$ \\
\hline Schumpeterian side & 1.21 & 1.50 & 1.61 \\
Dickensian side & 1.22 & 1.50 & 1.63 \\
\hline
\end{tabular}

Partitioning innovators into the historically early part of the fold had a dramatic effect of tightening the scatter plot and this effect was more apparent on the 'Schumpeterian' side of knowledge valley containing the more innovative organisations. Partitioning innovators downstream had two effects; it made the scatter plots slightly fuzzier than the control, it also appeared to make the difference between the results obtained from the two sides of the fold less dramatic.

These results are interpreted as meaning that concentrating innovators upstream facilitates the flow of Monte Carlo balls into a relatively tight stream from the origin. Conversely if there are few innovators upstream, then the Monte Carlo balls are well-distributed by the time they approach the area where the more concentrated partition starts, and thus many balls will simply not contact with the knowledge trail and will therefore not be captured by the downstream knowledge trail. However while interpreting 
these results one should be aware that sweeper code has been added to prevent balls going backwards, exactly as described previously (Mellor, 2011), and that relaxing the conditions in the sweeper code may to some extent affect these results.

\section{Conclusions}

The experimental findings imply that adding middle-management innovators to low-innovation SME environments can result in real bottom-line gains for the SME-sized organisations: The results indicate that low innovation organisations can profitably use multi-specialised individuals background [possessing 'T-shaped' or 'A-shaped' skills, (Tsai and Huang, 2008; Mellor, 2005)] in middle management top increase value, however that may be measured. Obviously providing that the skills brought in, and the innovations generated, are in close alignment with the company's core competencies (Quinn and Hilmer, 1995) then the modelling indicates that the company's general financial health may improve considerably. As the organisation opens up to further innovation, the strategic choices for the leadership are in all probability either to watch and control this process carefully, or to deliberately plunge through a major BPR-type transformation with the aim of becoming a high-innovation organisation. Obviously miscalculations at this point may have very unfortunate consequences for the organisation.

The experimental findings also imply that adding middle-management innovators to high-innovation SME environments can also lead to gains for the organisation but in this case the modelling indicates that these may not be absolute gains, but rather that the organisation continues to achieve the potential that knowledge valley says it should, but it may do so earlier or easier: However in contrast to low-innovation environments, high-innovation organisations can profitably use multi-specialised individuals in middle management even when the skills brought in, and the innovations generated, are not in close alignment with the company's core competencies, providing that the organisation involved can act in an innovative and entrepreneurial fashion by levering intrapreneurship (also known as Corporate Entrepreneurship, see Burns, 2008) and spinning out any initiatives that are not in alignment with the parent organisations core competencies. Obviously miscalculations at this point may have unfortunate consequences for the organisation, but the consequences of these are unlikely to be as serious as similar miscalculations made in low-innovation organisations.

Interestingly although the modelling indicates that high-innovation organisations may not achieve absolute gains by adding innovators in middle management salary brackets (the modelling indicates that the organisation continues to achieve its theoretical value, merely earlier or easier) the shape of the scatter plots for high-innovation organisations do not completely rule out that absolute increases in the organisations value can be achieved; the only point however where innovators can be added and the shape of the scatter plot exceeds the base curve is right at the very tip; the highest paid executive. Even at this point gains using the current model appear marginal, however as described below the current model contains constraints, and thus future experiments may clarify if adding innovators to top positions does in fact add value and may indicate how much.

Finally, the results obtained from placing innovators upstream and downstream (i.e., historically earlier or later in a developing organisation) strongly imply that hiring innovative managers into an existing and expanding medium-sized organisation that is 
already populated by a well-established class of less innovative managers can add value. The results also however imply that putting an innovative middle-management in place early in the development of an SME is significantly more likely to result in adding value for the organisation. Thus adopting high innovators from the very start implies the highest potential returns.

\section{Future directions}

For the sake of simplicity the fold and modelling presented here have hitherto been based on the assumptions that:

1 a person can have a very large number of ties, that there is no upper limit and all ties are within the organisation

2 all ties are exactly similar and have the same 'weight', quality and importance independent of their length.

Clearly these assumptions may be at variance with the literature and even at variance with common perception and consequently future models will investigate the effect of external networks and on "the strength of weak ties" (Granovetter, 1983).

\section{References}

Atherton, A. and Hannon, P. D. (2001) 'Innovation processes and the small business, a conceptual analysis', International Journal of Business Performance Management, Vol. 2, No. 4, pp.276-292.

Bessant, J. (1999) 'Developing continuous improvement capability', International Journal of Innovation Management, Vol. 2, No. 2, pp.409-429.

Birch, D.L. (1987) Job Creation in America, How Our Smallest Companies put the most People in Work, Free Press. New York.

Birkinshaw, J. and Sheehan, T. (2002) 'Managing the knowledge life cycle', MIT Sloan Management Review, Vol. 44, No. 1, pp.75-83.

Boisot, M. (1995) 'Is your firm a creative destroyer - competitive learning and knowledge flows in the technological strategies of firms', Research Policy, Vol. 24, No. 4, pp.489-506.

Burns, P. (2008) Corporate Entrepreneurship: Building an Entrepreneurial Organisation, 2nd ed., Palgrave Macmillan, Basingstoke.

Carneiro, A. (2000) 'How does knowledge management influence innovation and competitiveness?', Journal of Knowledge Management, Vol. 4, No. 2, pp.87-98.

Farrell, M.A. (2000) 'Developing a market-oriented learning organisation', Australian Journal of Management, Vol. 25, No. 2, pp.201-223.

Granovetter, M. (1983) 'The strength of the weak tie revisited', Sociological Theory, Vol. 1, pp.201-233.

Holmes, S and Zimmer, I. (1994) 'The nature of the small firm, understanding the motivation of growth and non-growth oriented owners', Australian Journal of Management, Vol. 19, No. 1, pp.97-120.

Iansiti, M. (1993) 'Real world Rand; jumping the product generation gap', Harvard Business Review, Vol. 71, No. 3, pp.138-147.

Katz, R. (2004) 'The motivation of professionals', in Katz, R. (Ed.): The Human Side of Managing Technological Innovation, pp.3-20, Oxford University Press, Oxford. 
Kauffman, S. (1993) The Origins of Order: Self-Organization and Selection in Evolution, Oxford University Press, Oxford.

Kotler, P. and de Bes, F.T. (2003) Lateral Marketing, John Wiley. New York.

Leitch, C., Hill, F. and Neergaard, N. (2010) 'Entrepreneurial and business growth and the quest for a 'comprehensive theory': tilting at windmills?', Entrepreneurship Theory and Practice, Vol. 34, No. 2, pp.249-260.

McCarthy, I.P. (2008) 'Manufacturing fitness and NK models', in G. Frizelle and H. Richards (Eds.): Tackling Industrial Complexity, Institute for Manufacturing, Cambridge, UK [online] http://www.ifm.eng.cam.ac.uk/mcn/proceedings.htm (accessed January 2008).

Mellor, R.B. (2005) Sources and Spread of Innovation in Small E-commerce Companies, Globe, Copenhagen.

Mellor, R.B. (2011) Knowledge Management and Information Systems, Strategies for Growing Organizations, Palgrave Macmillan, Basingstoke.

Mellor, R.B. (2014) 'Knowledge valley theory', International Journal of Knowledge Based Development, Vol. 5, No. 1, pp.1-16.

Porter, M.E. (1980) Competitive Strategy, The Free Press, New York.

Porter, M.E. (1990) The Competitive Advantage of Nations, Palgrave Macmillan, Basingstoke.

Quinn, J.B. and Hilmer, F.G. (1995) 'Strategic outsourcing', McKinsey Quarterly, Vol. 1, pp.48-70.

Storey, D.J. (2011) 'Optimism and chance, the elephants in the entrepreneurship room', International Small Business Journal, Vol. 29, No. 4, pp.303-321.

Suppiah, V. and Sandhu, M.S. (2011) 'Organisational culture's influence on tacit knowledgesharing behaviour', Journal of Knowledge Management, Vol. 15, No. 3, pp.462-477.

Tsai, M-T. and Huang, Y-C. (2008) 'Exploratory learning and new product performance: the moderating role of cognitive skills and environmental uncertainty', The Journal of High Technology Management Research, Vol. 19, No. 2, pp.83-93.

Williamson, O.E. and Masten, S.E. (1999) The Economics of Transaction Costs, Edward Elgar Publishing, New York.

Yang, H-D., Kang, H-R. and Mason, R.M. (2008) 'An exploratory study on meta skills in software development teams: antecedent cooperation skills and personality for shared mental models', European Journal of Information Systems, Vol. 17, pp.47-61.

Yuan, Y. and Mckelvey, B. (2004) 'Situated learning theory: adding rate and complexity effects via Kauffman's NK model', Nonlinear Dynamics, Psychology, and Life Sciences, Vol. 8, pp.65-102. 